\title{
Design of Thermal Barrier Coatings Thickness for Gas Turbine Blade Based on Finite Element Analysis
}

\author{
Biao Li, ${ }^{1}$ Xueling Fan, ${ }^{1}$ Dingjun Li, ${ }^{1,2}$ and Peng Jiang ${ }^{1}$ \\ ${ }^{1}$ State Key Laboratory for Strength and Vibration of Mechanical Structures, School of Aerospace Engineering, \\ Xian Jiaotong University, Xian 710049, China \\ ${ }^{2}$ Dongfang Steam Turbine Co., Ltd., Deyang 618000, China
}

Correspondence should be addressed to Xueling Fan; fanxueling@mail.xjtu.edu.cn

Received 8 May 2017; Accepted 5 June 2017; Published 6 July 2017

Academic Editor: Fabrizio Greco

Copyright (C) 2017 Biao Li et al. This is an open access article distributed under the Creative Commons Attribution License, which permits unrestricted use, distribution, and reproduction in any medium, provided the original work is properly cited.

\begin{abstract}
Thermal barrier coatings (TBCs) are deposited on the turbine blade to reduce the temperature of underlying substrate, as well as providing protection against the oxidation and hot corrosion from high temperature gas. Optimal ceramic top-coat thickness distribution on the blade can improve the performance and efficiency of the coatings. Design of the coatings thickness is a multiobjective optimization problem due to the conflicts among objectives of high thermal insulation performance, long operation durability, and low fabrication cost. This work developed a procedure for designing the TBCs thickness distribution for the gas turbine blade. Three-dimensional finite element models were built and analyzed, and weighted-sum approach was employed to solve the multiobjective optimization problem herein. Suitable multiregion top-coat thickness distribution scheme was designed with the considerations of manufacturing accuracy, productivity, and fabrication cost.
\end{abstract}

\section{Introduction}

Thermal barrier coatings (TBCs) are widely used in advanced gas turbines to provide the thermal and oxidation protection to metallic substrate against high temperature gas $[1,2]$. Application of TBCs can significantly improve the performance and efficiency of the turbines. A typical TBC system is composed of a load carrying substrate, a ceramic top-coat (TC), a metallic bond-coat (BC), and the thermally grown oxide (TGO) that forms between TC and BC.

Generally, the temperature decreases across TBCs at specific operation condition are governed by the material and geometrical properties of the TC layer, especially the thermal conductivity and thickness [3-9]. For a given ceramic material, the thermal insulation capability of the coatings enhances with the increase of TC thickness. Nevertheless, the thermal mismatch stress within the coatings may also increase simultaneously. It is recognized that there exists a balance between the thermal insulation capability and thermal stress level. Determination of suitable TC thickness for the hot components becomes an optimization problem.
Optimal design of TBCs thickness for gas turbine blade can improve the performance and efficiency of the coatings. It is desirable to have an available, simple, and efficient approach to design the coatings for engineering application. Unfortunately, little work has been reported on this issue. Most investigations about the turbine blade deal with the substrate without TBCs, which fails to take into account the influence induced by the coatings, such as failure analysis of the blade [10-12], heat transfer simulation [13, 14], or design of cooling channels [15]. A few works raised concerns about TBCs on the real turbine blade. For instance, Sohn et al. [16] experimentally investigated the microstructural development of TBCs in high pressure turbine blade before and after the service. Significant sintering and phase transformation were observed, and localized spallation of yttria partially stabilized zirconia (YSZ) was found near the tip of the serviced blade. Gurrappa and Rao [17] conducted the hot corrosion experiments on cylindrical specimens having various TBCs thicknesses and figured out that an optimum thickness of TBCs can enhance the life of underlying superalloy by about six hundred times. Yang et al. [18] developed finite element 


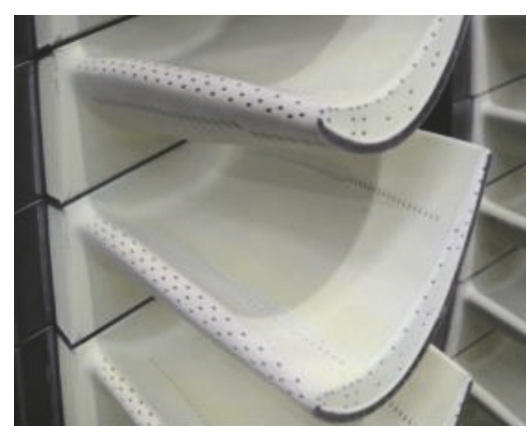

(a)

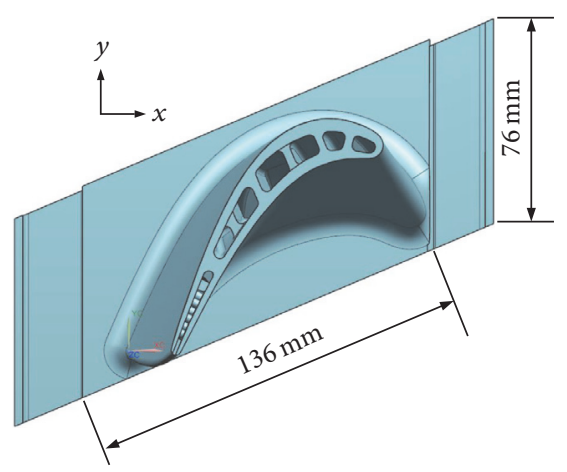

(d)

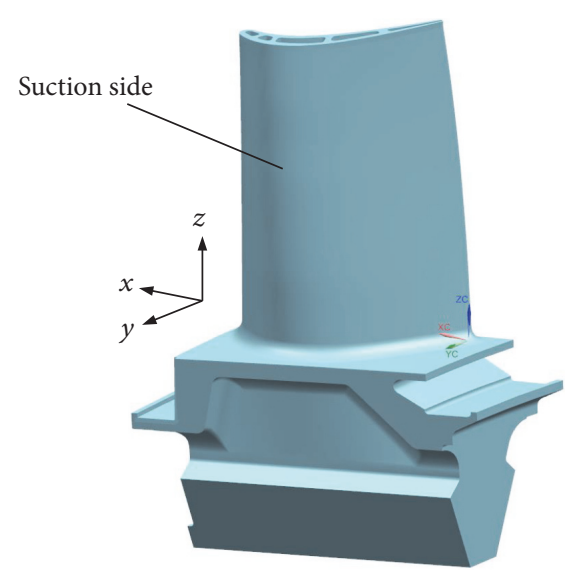

(b)

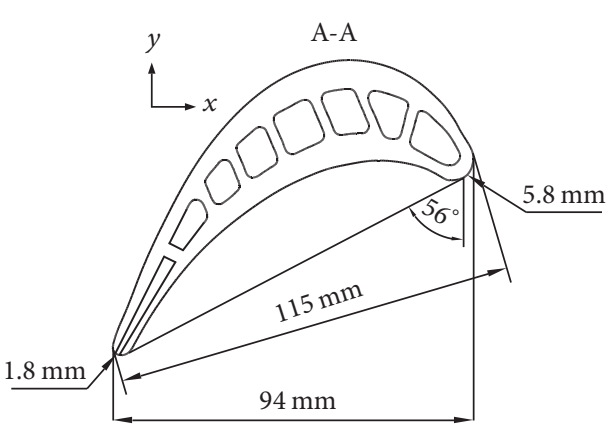

(e)

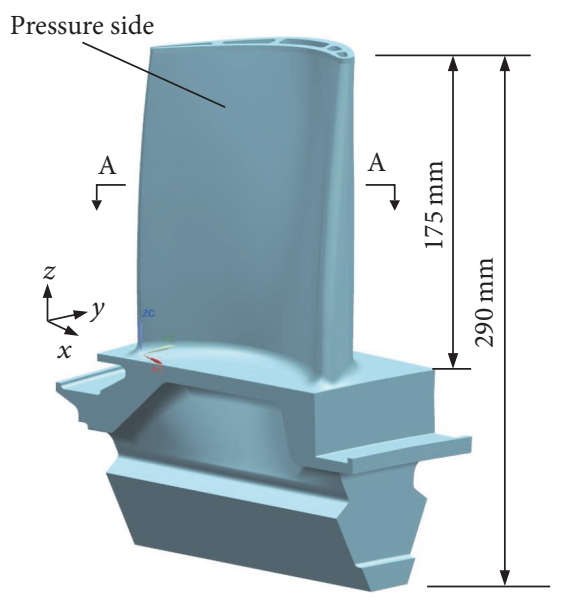

(c)

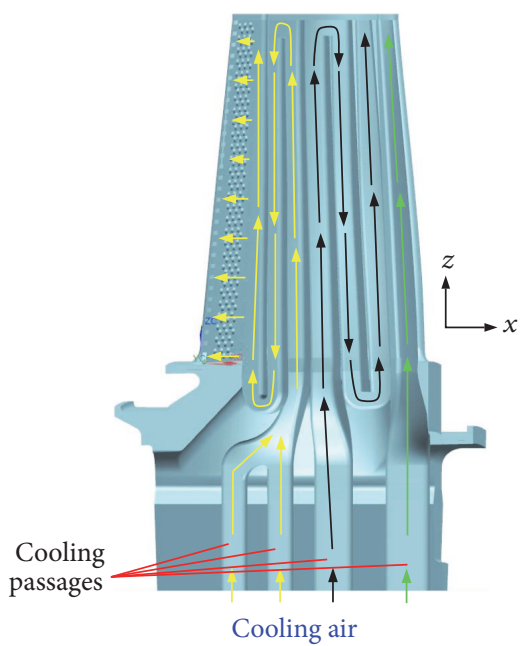

(f)

FIGURE 1: Geometries of a gas turbine rotor blade: (a) blades mounted around a rotor disk, (b) suction side view, (c) pressure side view, (d) top view, (e) dimensions of cross section A-A, and (f) internal cooling passages.

(FE) model for the blade with TBCs to investigate the failure behavior under cyclic thermal loading. Zhu et al. [19] studied the effect of morphology of TGO on stress distribution in a turbine blade with TBCs under cyclic thermal loading.

Above works provided insight into the influence of TBCs on turbine blade. However, none of them deals with the issue of design of TBCs thickness. Actually, due to the difficulty in meshing a real gas turbine blade having complex external and internal geometry shapes, most numerical works instead utilized two-dimensional or simplified three-dimensional model in their simulations. For example, Yang et al. [18] and Zhu et al. [19] used the simplified three-dimensional FE models in which the blade airfoil uniformly and straightly extends from platform to the tip, and a single cooling passage is assumed as well. It should be pointed out that the simplified models can hardly reflect temperature and stress fields in the real blade which thus leads the obtained conclusions to become circumscribed.
This work aims to develop a procedure for designing TBCs thickness distribution for gas turbine blade. Sophisticated three-dimensional FE model of the turbine blade with TBCs is built and analyzed. The optimization design procedures are presented and applied to obtain the preliminary thickness distributions. Finally, suitable TC thickness distribution scheme is determined according to the quantitative comparison. This work provides a primary coating distribution scheme for turbine blade.

\section{Finite Element Modeling}

2.1. Geometry and Meshing. The blade investigated in this work is a first-stage rotor blade in a gas turbine, as shown in Figure 1. It has complex external and internal geometries, which includes an airfoil having concave pressure side and convex suction side, a platform defining the boundary for the hot gas, and a supporting shank positioned below the 


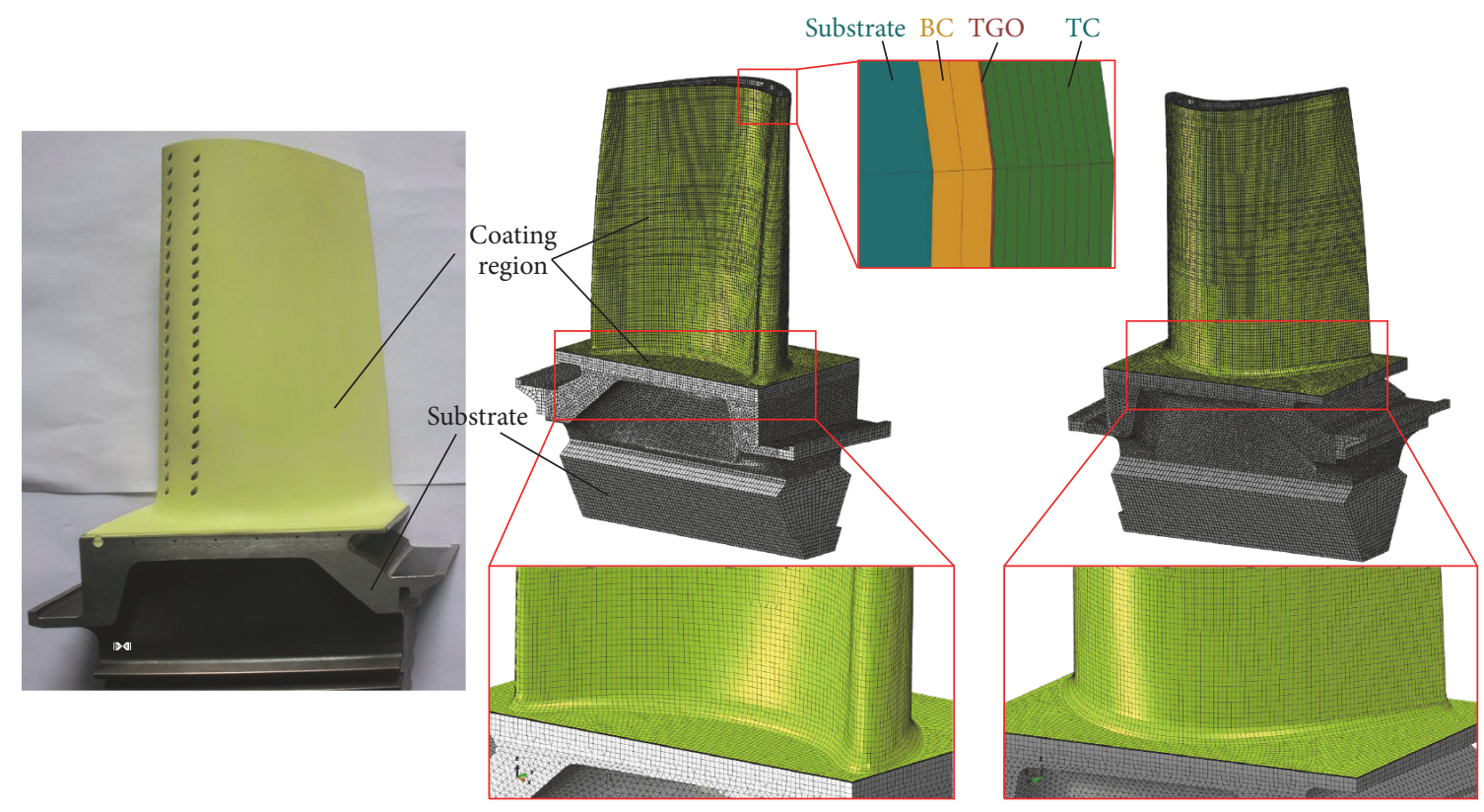

FIgURE 2: Finite element model of gas turbine blade with TBCs.

platform. The blade is hollow and includes multiple serpentine cooling passages for receiving the pressurized cooling air. The blade root which can attach the blade to rotor disk is not included in present model, since it has little influence on the problem we are concerned with. As can be seen in Figure $1(\mathrm{~d})$, the airfoil has a feature of twisting around the radial centerline when extending radially outward from the platform to the blade tip. The dimension of a cross section of the airfoil is shown in Figure 1(e).

The complexity of geometry makes it challenging to mesh the turbine blade. We built the three-dimensional FE model by using a combination of Altair HyperMesh and ABAQUS packages. Generally, the geometrical model of the substrate built in CAD software was firstly imported into HyperMesh and then meshed with hexahedron and tetrahedron elements. The FE model was subsequently imported into ABAQUS as orphan mesh geometry. The mesh offset technique provided by ABAQUS, which can generate solid mesh layers by offsetting a mesh surface along its normal direction, was then applied to generate mesh layers of TC, TGO, and BC. Small geometrical details of the substrate were defeatured to avoid small elements when generating mesh using HyperMesh. The blade airfoil, platform, and bottom part of the shank were mostly meshed with 8-node solid hexahedron elements except those with bad quality which were replaced by linear tetrahedron elements. The remaining part of the shank was meshed with linear tetrahedron elements, since it is impossible for it to be meshed with hexahedron elements, attributing to its complex external and internal geometries. According to the engineering practice, as shown in Figure 2, the outer surface of the airfoil and the top surface of the platform are coated with TBCs.

The nominal mesh sizes of the airfoil and platform were chosen as $0.8 \mathrm{~mm}$, and the nominal mesh size is $2.5 \mathrm{~mm}$ for the shank. The thickness of TC varies in different analysis cases. BC is constantly $150 \mu \mathrm{m}$ thick and is meshed with two layers of elements in all models. TGO is also modelled in the analysis with a thickness of $5 \mu \mathrm{m}$. It should be pointed out that this work does not intend to simulate the growth of TGO, but the large elastic modulus mismatch among TGO and neighboring layers has a significant influence on the stress field $[20,21]$, which makes it necessary to include TGO layer in the models. However, dividing TGO into multiple layers of elements can lead to very large element aspect ratio. Thus, it is modeled with one single layer of elements. This choice of mesh density may cause some numerical disturbance, but the analysis accuracy is believed to be sufficient to obtain the design scheme.

The total number of elements is approximately 1.0 million, including 0.62 million of hexahedron elements (C3D8R), 0.36 million of tetrahedron elements (C3D4), and 0.02 million of triangular prism elements (C3D6). The mesh sensitive analysis was conducted. The mesh sizes used in the simulations can obtain adequate computational accuracy and ensure acceptable cost.

2.2. Material Properties and Boundary Conditions. The TBCs are composed of APS $\mathrm{ZrO}_{2}-8 \mathrm{wt} \% \mathrm{Y}_{2} \mathrm{O}_{3}$ (8YSZ) TC layer, $\alpha-\mathrm{Al}_{2} \mathrm{O}_{3}$ TGO layer, NiCrAlY BC layer, and nickel superalloy substrate. All layers are considered to be isotropic, homogenous, and temperature-independent. The materials properties are listed in Table 1.

A uniform temperature boundary condition was imposed on the blade without taking into account the thermal radiation and convection. According to the typical thermal conditions in turbine engine $[13,18,22]$, the TC surface is 
TABLE 1: Materials properties used in the finite element model [23, 24].

\begin{tabular}{|c|c|c|c|c|}
\hline Material properties & Top-coat & TGO & Bond-coat & Substrate \\
\hline Elasticity modulus (GPa) & 48.0 & 400 & 200 & 220 \\
\hline Poisson's ratio & 0.1 & 0.23 & 0.3 & 0.31 \\
\hline Thermal expansion coefficient $\left(\times 10^{-6} /{ }^{\circ} \mathrm{C}^{-1}\right)$ & 9.0 & 8.0 & 13.6 & 12.6 \\
\hline Thermal conductivity $\left(\mathrm{W} / \mathrm{m}^{\circ} \mathrm{C}\right)$ & 1.2 & 10.0 & 5.8 & 11.5 \\
\hline
\end{tabular}

heated from $20^{\circ} \mathrm{C}$ to $1150^{\circ} \mathrm{C}$, and the inner surface of cooling passages is heated from $20^{\circ} \mathrm{C}$ to $700^{\circ} \mathrm{C}$ simultaneously, both of which are assumed to be implemented in sufficient time to reach a steady state. The ENCASTRE boundary condition is assigned to the bottom surface of blade shank in stress analysis.

2.3. Thermal and Stress Analysis. The evaluations of stress and temperature fields are carried out in ABAQUS by using the sequentially coupled method. This method considers a oneway interaction between stress/deformation and temperature, which is often used for problems where stress field depends on the temperature field, but the reverse is not significant. It is implemented by first conducting an uncoupled steadystate heat transfer analysis and then a stress analysis. Nodal temperature taken from the former analysis is imported into stress analysis as a predefined temperature field.

\section{Design of Top-Coat Thickness for Turbine Blade}

3.1. Optimization Approach. Generally, the in-service performance, durability, and fabrication cost are three main objectives in determining TBCs thickness for a gas turbine blade. Parameters should be carefully selected to represent above objectives.

For in-service performance aspect, thermal insulation capability is the most important requirement. Application of high thermal insulation TBCs can reduce the temperature of substrate to prolong its lifetime or allows increasing the turbine inlet temperature and thereby improving the engine efficiency. Thus, the temperature difference between TC surface and substrate surface is considered as a performance parameter. Larger temperature decreases across the coatings mean better thermal insulation performance.

The durability of TBCs is mainly related to the intrinsic failure mechanisms of the coatings. Interfacial delamination is one of the major weaknesses of the coatings. Higher thermal stress gives rise to premature delamination and shorter lifetime. Delamination may be avoided when the stresses are low enough. Therefore thermal stress is considered as a parameter controlling the durability of TBCs, which should not exceed a critical value and should be kept as low as possible.

Moreover, the fabrication cost and technical difficulties increase while using thick TBCs, which indicates that thinner TBCs are preferred. The TC thickness is chosen as a parameter to characterize the fabrication cost.
Taking into account the above factors, design of TBCs thickness is a multiobjective optimization problem, which can be formulated as follows.

$$
\begin{array}{ll}
\text { Minimize: } & g_{\mathrm{obj}}=\left[\sigma_{\mathrm{TC}}(h), \frac{1}{\Delta T(h)}, h\right]^{T} \\
\text { subject to: } & h_{l} \leq h \leq h_{u} \\
& \sigma_{\mathrm{TC}}(h) \leq \sigma_{\mathrm{TC}}^{\mathrm{cr}} \\
& T_{\mathrm{sub}} \leq T_{\mathrm{sub}}^{\mathrm{cr}}
\end{array}
$$

where $h$ is design variable that denotes the TC thickness, $\sigma_{\mathrm{TC}}(h)$ is the maximum von Mises stress within TC, and $\Delta T(h)$ is the temperature difference between the TC surface and the substrate surface.

In this work, $h_{l}$ and $h_{u}$ are assumed to be $100 \mu \mathrm{m}$ and $800 \mu \mathrm{m}$, respectively. It is known that thick TC can cause high residual stress during spraying and may potentially have influence on the gas flowing area. Thus, we assign the upper limit of TC thickness, $h_{u}$, as $800 \mu \mathrm{m}$. The critical allowed stress in TC, $\sigma_{\mathrm{TC}}^{\mathrm{cr}}$, is assigned as an experimentally measured biaxial strength of $174 \mathrm{MPa}$ [25]. The temperature on the superalloy substrate, $T_{\text {sub }}$, is assumed to be no higher than the critical value, $T_{\text {sub }}^{\mathrm{cr}}=1000^{\circ} \mathrm{C}$.

To make the problem easier, an evaluation parameter, $\beta$, is defined to estimate the comprehensive thermal and mechanical performances of the TBCs as follows:

$$
\beta(h)=\frac{\sigma_{\mathrm{TC}}(h)}{\Delta T(h)} .
$$

Obviously, smaller value of $\beta$ means better performance of the TBCs. By using the single scalar evaluation parameter, the objectives of low stress level and high thermal insulation are combined together.

The objective function in (1) is defined to have the targets of low stress level, high thermal insulation, and low fabrication cost. However, there are conflicts among these objectives. For instance, the thermal insulation performance improves with the increase of TC thickness, but the induced thermal stress and fabrication cost are also enhanced. No optimal solution exists to minimize all the functions simultaneously. Rather, the optimization is likely to result in a set of points that constitute Pareto front [26-28]. Many weakly Pareto optimal solutions exist for the problem. It is often necessary to incorporate preference conditions in order to determine a single suitable solution.

It should be mentioned that this work aims to develop a procedure to design the TBCs thickness instead of focusing on complex optimization algorithm. Thus, the classical 


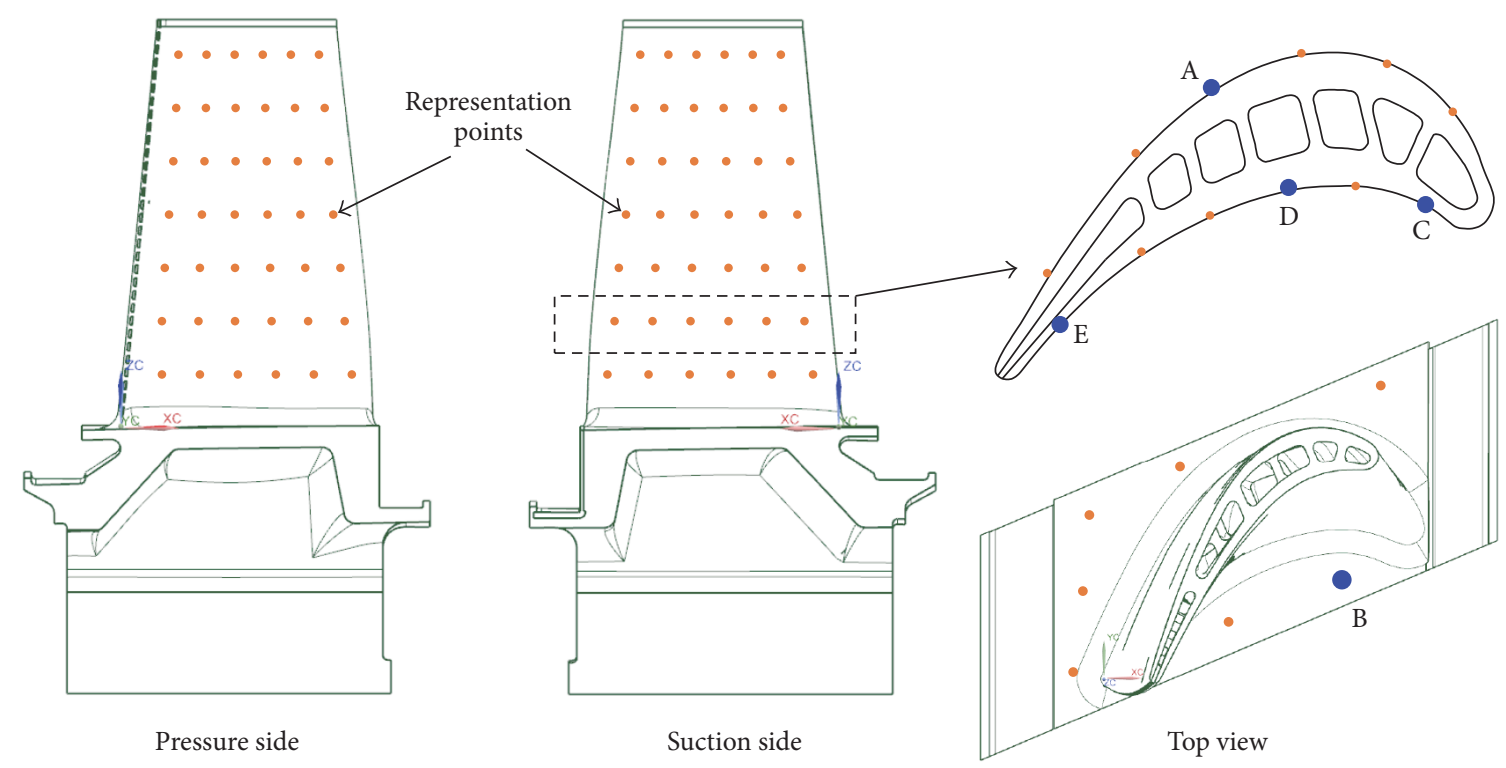

FIGURE 3: Distribution of the representative positions on the blade.

weighted-sum approach is employed to solve the multiobjective problem herein. However, other advanced optimization algorithms, such as evolutionary algorithm [29], genetic algorithm [30], particle swarm algorithm [31], and simulated annealing algorithm [32], are still valid in the design procedure.

By using the weighted-sum approach, the multiple objectives are scalarized into a single scalar objective as

$$
\text { Minimize: } \quad g_{\text {obj }}=w_{\beta} f_{\beta}+w_{h} f_{h} \text {, }
$$

where $f_{\beta}$ and $f_{h}$ are objectives of performance and TC thickness, respectively, which are expressed as

$$
\begin{aligned}
& f_{\beta}=\beta(h), \\
& f_{t}=h .
\end{aligned}
$$

Generally, the sum of all scalar weights equals one; namely, $w_{\beta}+w_{h}=1$, with $w_{\beta}, w_{h} \geq 0$. Selection of scalar weights affects the optimal TC thickness at a representative position. Larger $w_{\beta}$ means better performance is preferred and thicker TC should be used.

In general, the assignment of weights depends on the designer's decision. In this work, considering that higher performance of TBCs is more attractive, we empirically choose the weight $w_{\beta}=0.6$ for the performance objective and $w_{h}=0.4$ for the fabrication cost objective. Actually, we have examined the sensitivity of design scheme to the scalar weights. It is found that different weights in part affect the optimal TC thickness at some representative positions, but this weight has insignificant influence on the determination of design scheme when the weights are within some extent; for example, schemes resolved from $w_{\beta}=0.6$ and 0.7 are identical to each other.
The objective function in (3) only aims at finding suitable TC thickness for a single position on the blade. To evaluate the superiority of a thickness distribution scheme, a series of representative positions on the blade need to be selected and their total sum of objective functions is employed, which is given as

$$
G_{\mathrm{obj}}=\sum_{i=1}^{n} g_{\mathrm{obj}}^{i},
$$

where $n$ is the number of selected representative positions, $g_{\text {obj }}^{i}$ is the objective function of $i$ th position, and $G_{\text {obj }}$ is the sum of all objective functions. It seems that an optimization design scheme having smaller value of $G_{\text {obj }}$ is preferred. However, the feasibility and complexity of the fabrication process are other important factors that must be taken into account during the final selection of scheme.

3.2. Optimization Design Procedure. The optimization design procedure can be divided into three main processes: preliminary analysis, optimization design, and scheme verification:

(i) In the preliminary analysis process, FE models with uniform TC thickness are analyzed, and $g_{\text {obj }}^{i}$ at the every representative position is calculated. Ten uniform-thickness schemes are considered in this work, in which TC thicknesses range from $100 \mu \mathrm{m}$ to $1000 \mu \mathrm{m}$ with an increment of $100 \mu \mathrm{m}$. There are totally 91 positions in this analysis, including 84 on the blade airfoil and 7 on the platform, as shown in Figure 3.

(ii) In the optimization design process, the weighted-sum method is applied for each representative position to find an optimal TC thickness. Note that the representative position stands for a region having 


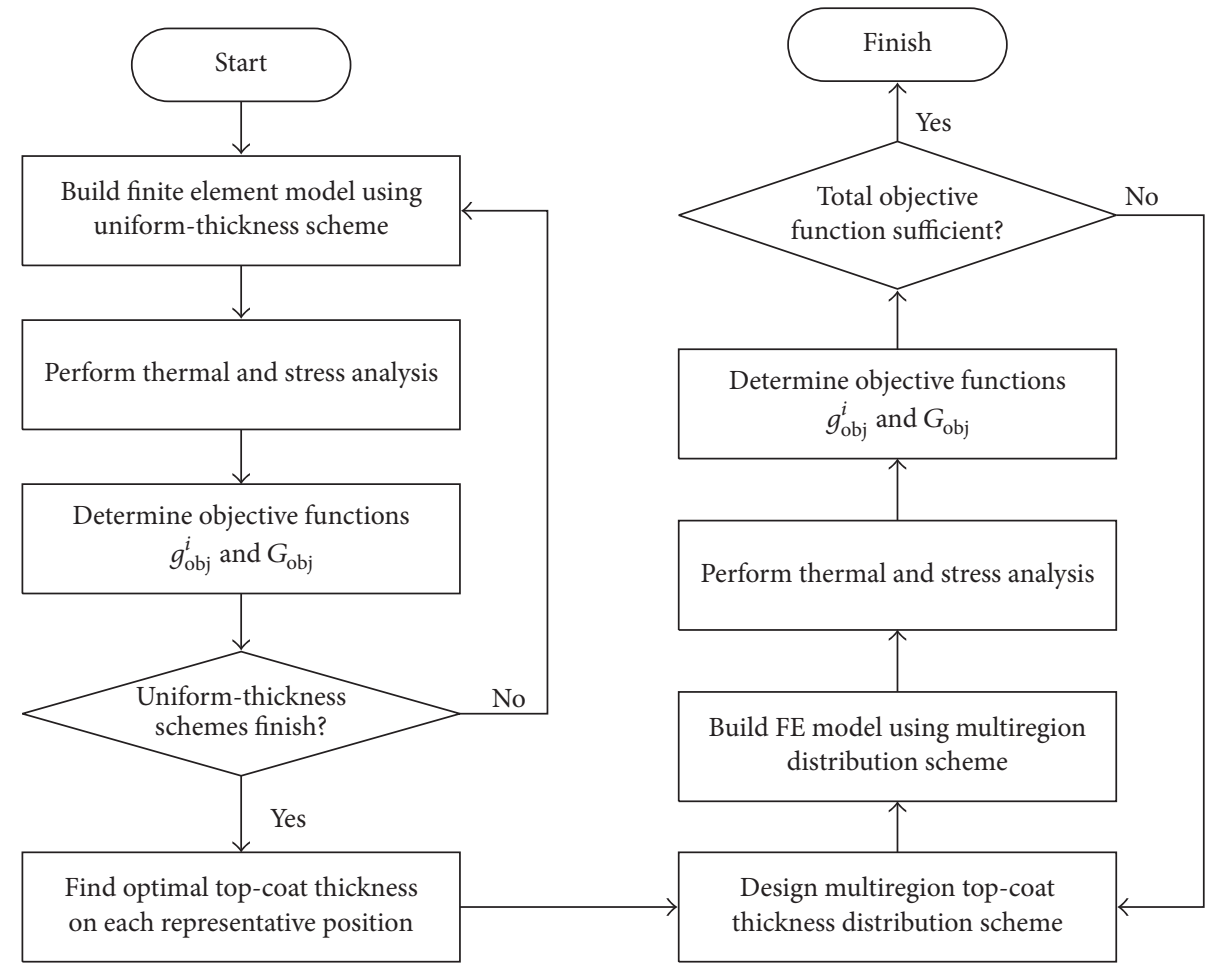

FIGURE 4: Optimization design procedure of thermal barrier coating thickness.

the same TC thickness. According to the preliminary optimal thickness distributions, the overall coating region is divided into multiple subregions to form the multiregion scheme.

(iii) In the scheme verification process, FE model using the multiregion scheme is built and analyzed, and the total objective function $G_{\text {obj }}$ is calculated. Note that the magnitude of $G_{\mathrm{obj}}$ depends on the quantity and distribution of the representative positions. It is difficult to predefine a universal value of $G_{\text {obj }}$ to evaluate the superiority of a scheme for any given analysis. Thus, the available way is to compare $G_{\text {obj }}$ of a multiregion scheme with those of the uniformthickness schemes. The superiority of different optimization schemes will be known from the reduction in total objective function.

The detailed optimization procedure is shown in Figure 4 and can be described in the following steps.

Step 1. Build FE model for the turbine blade using uniformthickness scheme, where TC is assigned to be uniform throughout the coating region.

Step 2. Perform thermal and stress analysis using the sequentially coupled method, and the overall temperature and stress fields are obtained.

Step 3. Select the representative positions on the blade and determine their objective functions $g_{\mathrm{obj}}^{i}$. Calculate the total objective function $G_{\text {obj }}$ for current uniform-thickness scheme.

Step 4. Judge whether all the uniform-thickness schemes have been finished. If not yet, go back to Step 1. Otherwise, calculate the optimal TC thickness using the weighted-sum method for each representative position.

Step 5. Design a multiregion TC thickness distribution scheme.

Step 6. Build FE model using the multiregion scheme obtained in Step 5 and perform thermal and stress analysis.

Step 7. Calculate the total objective function $G_{\text {obj }}$.

Step 8. Compare $G_{\text {obj }}$ of the multiregion scheme with those of the uniform-thickness schemes. If the reduction in total objective function is satisfied, the optimization design is finished. Otherwise, go back to Step 5.

\section{Numerical Results and Discussions}

4.1. Results of Uniform-Thickness Scheme. When using the uniform-thickness scheme, the TC thickness is uniform throughout the coating region. Typical temperature field and that of the substrate are shown in Figure 5 (taking the $500 \mu \mathrm{m}$ uniform thickness scheme as example). The high temperature region on the substrate is generally located at root of the airfoil, especially at the blade platform. The trailing edge has 


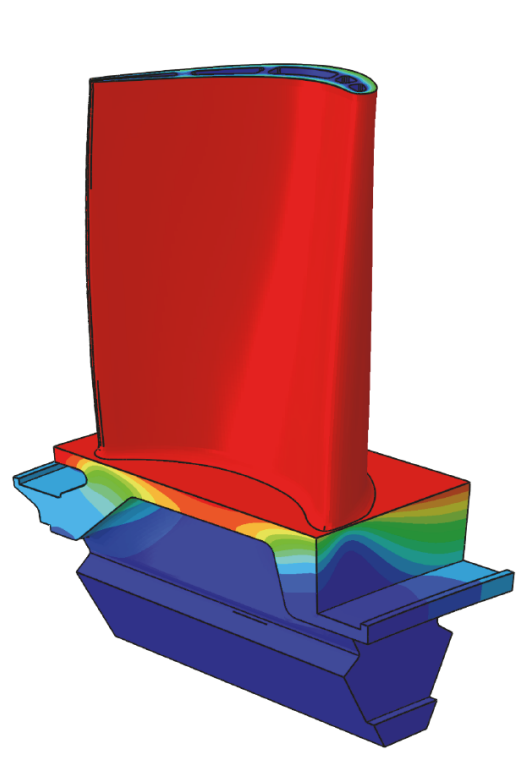

(a)

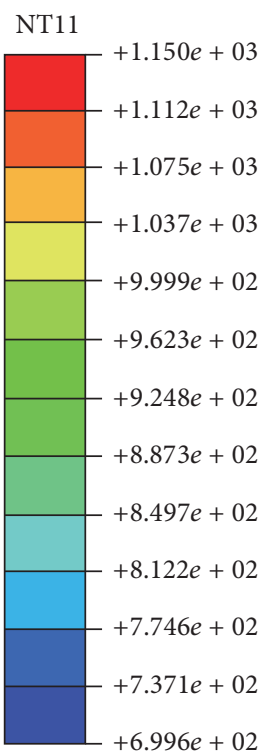

$+6.996 e+02$

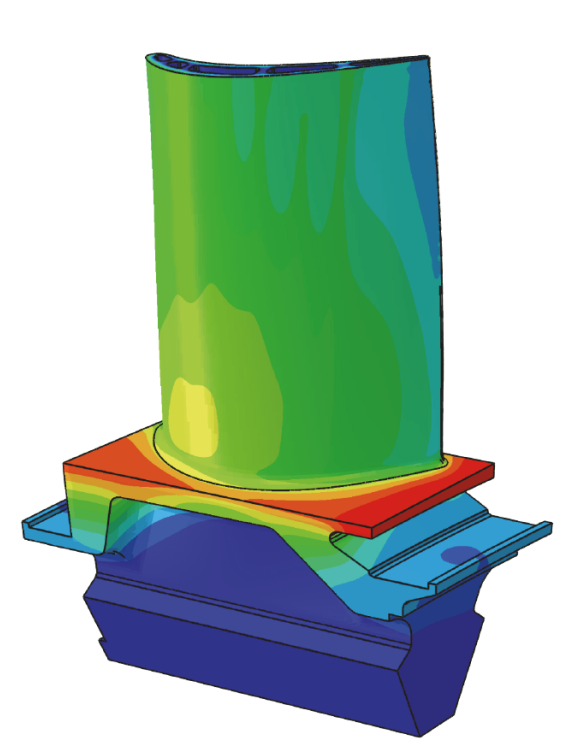

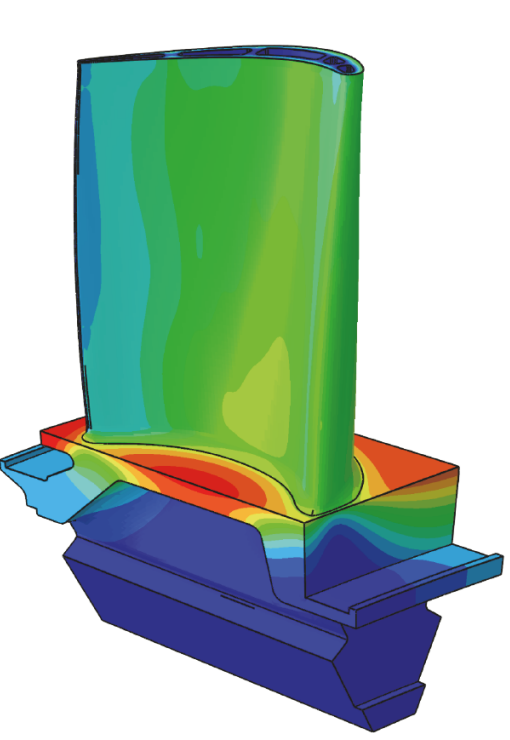

(b)
NT11

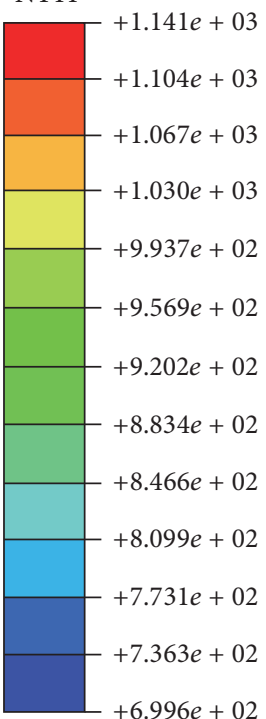

NT11

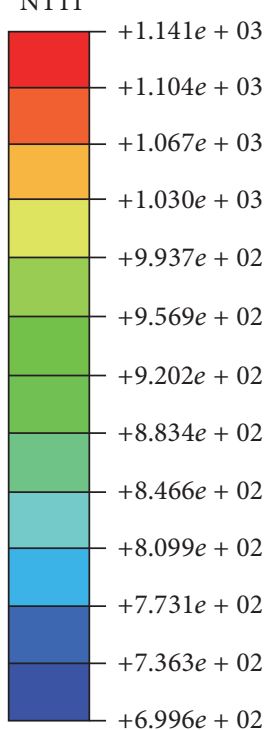

(c)

Figure 5: Temperature fields of the turbine blade (take model of $500 \mu \mathrm{m}$ uniform top-coat thickness as example): (a) overall model (with TBCs), (b) pressure side of the substrate (without TBCs), and (c) suction side of the substrate (without TBCs).

much lower temperature than leading edge due to the thin substrate and effective internal cooling therein.

Overall, the FE analysis shows that as the TC thickness increases, the temperature on the airfoil of the substrate is impressively decreased, but the platform is not apparent. To explain the difference between these two parts, typical representative positions $\mathrm{A}$ and $\mathrm{B}$ are selected and their temperature distributions are given in Figure 6, where paths are defined to be from $\mathrm{TC}$ surface to the $\mathrm{BC} /$ substrate interface. The distributions are generally bilinear, in which lines at left side represent the decrease within TC and the right ones denote the variation within TGO and BC. The thermal barrier effect at position $\mathrm{B}$ is not significant due to the fact that the platform is far away from internal cooling passages. For example, when the TC thickness is $1000 \mu \mathrm{m}$, the temperature reduction at position $\mathrm{A}$ is about $240^{\circ} \mathrm{C}$, while it is $100^{\circ} \mathrm{C}$ at position $\mathrm{B}$. The temperature gradient is reduced for thicker $\mathrm{TC}$ at position $\mathrm{A}$, but it is almost unchanged at position $\mathrm{B}$.

The von Mises stress distributions are presented in Figure 7, where paths are defined from TC surface to the TC/TGO interface. It is shown that stresses at both positions increase from TC surface and reach the maximum at TC/TGO interface, and surface stress in thinner TC is higher than that of thick TC. It is interesting that the maximum stress 


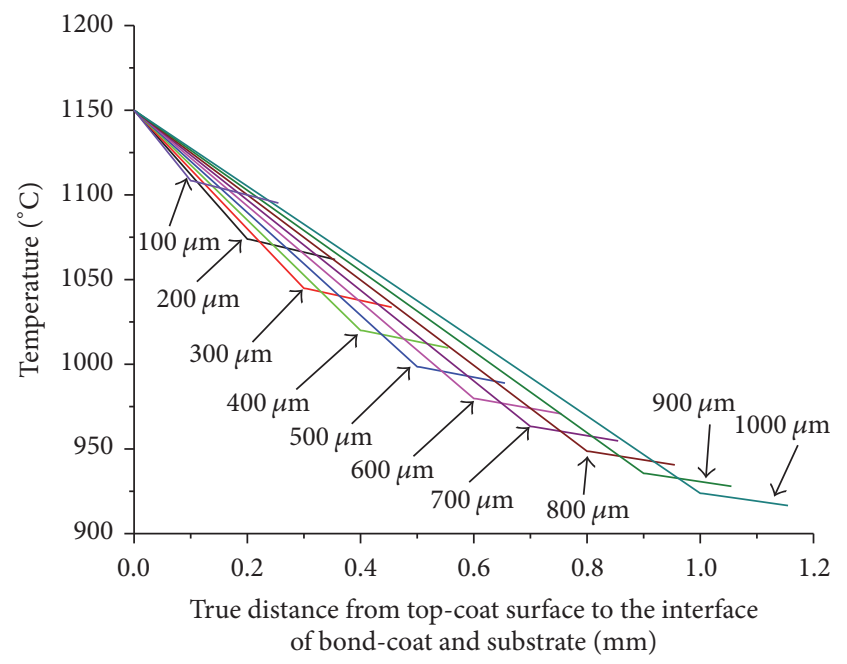

(a)

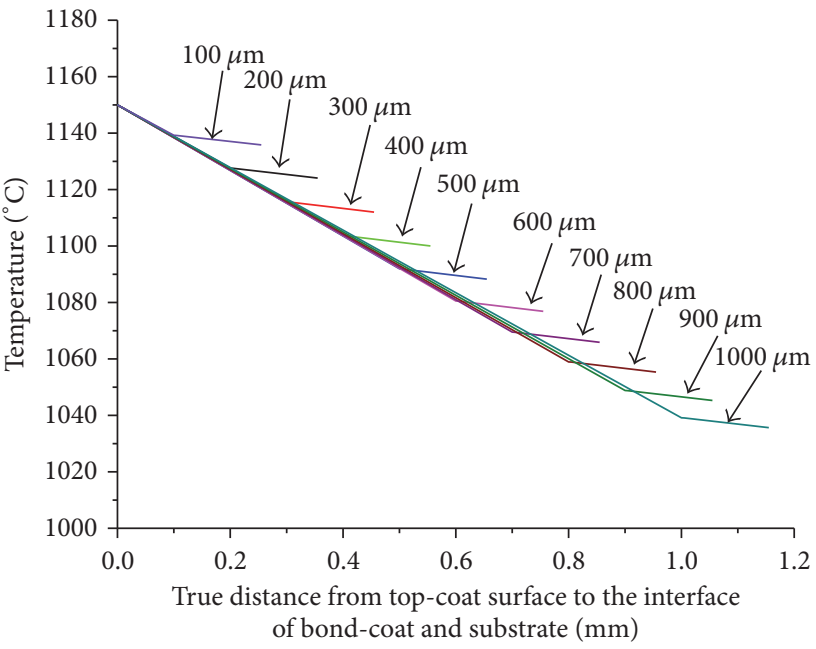

(b)

FIGURE 6: Temperature distribution in the coatings with the variation of top-coat thickness on (a) position A (on the airfoil) and (b) position B (on the platform).

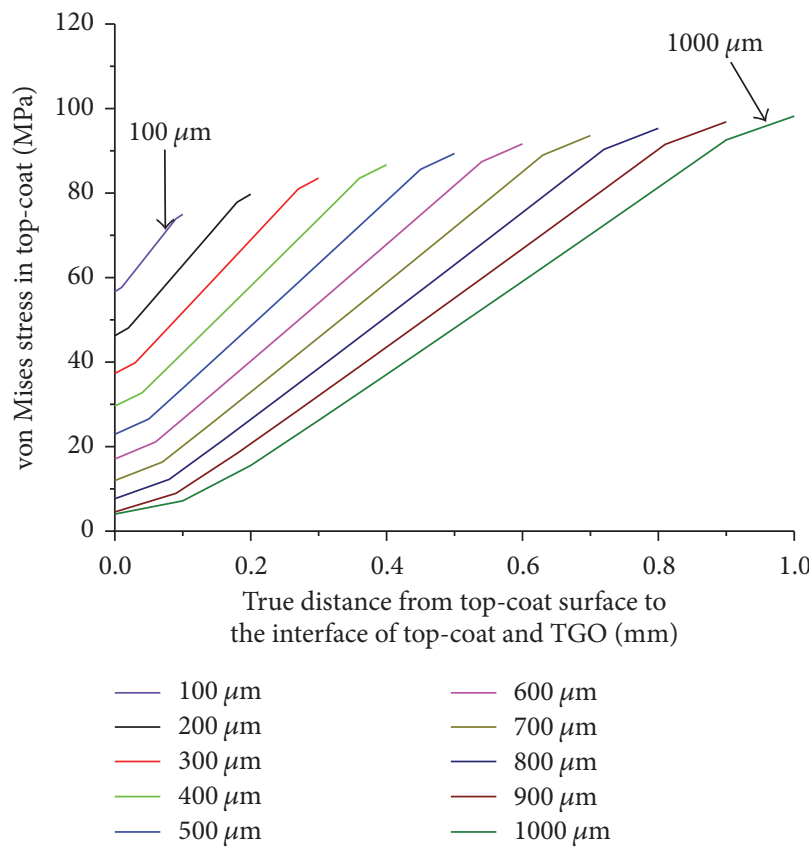

(a)

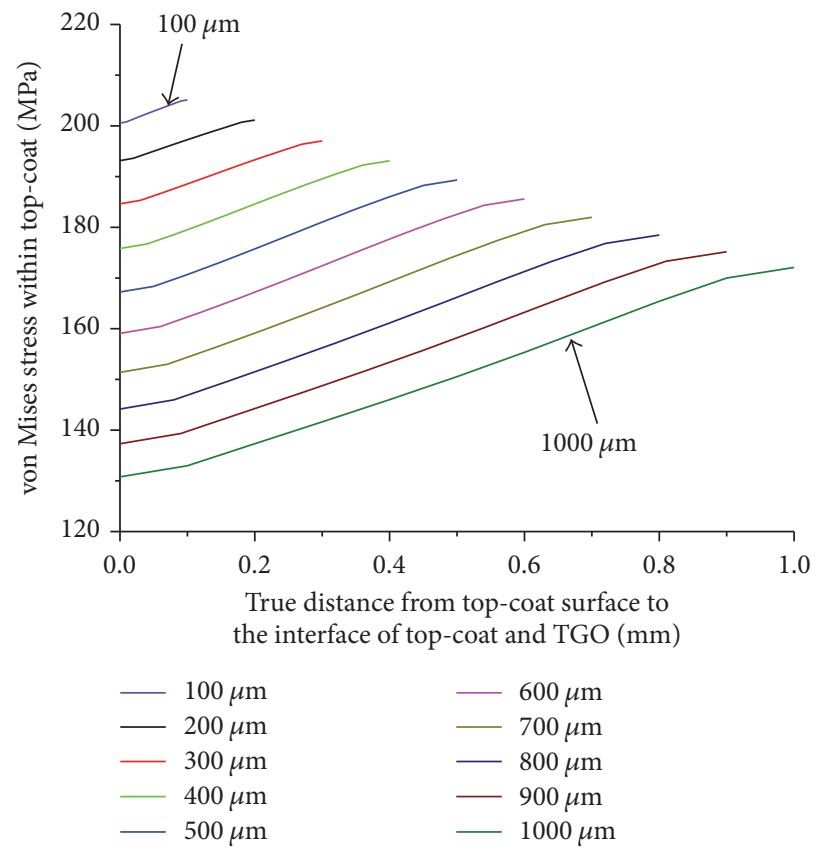

(b)

FIGURE 7: Stress distribution within top-coat with the variation of its thickness on (a) position A (on the airfoil) and (b) position B (on the platform).

increases with the increase of TC thickness for position A, but it is reverse for position B. It can be explained by the low temperature gradient at the platform, which also leads to the low stress gradient. The above results imply that the blade platform should be coated with as thick TC as possible.

The Pareto sets for typical representative positions A, C, D, and E (see Figure 3 ) represent suction side, leading edge, pressure side, and trailing edge on the airfoil, respectively, as shown in Figure 8. The Pareto fronts of these four representative positions are convex. Actually, the Pareto fronts of all representative positions on the blade are convex and meet the requirement of weighted-sum method.

The optimal TC thicknesses for all the representative positions on the airfoil are determined and the preliminary optimal thickness distribution is illustrated in the form of region contour, as shown in Figure 9(a). The thickness 


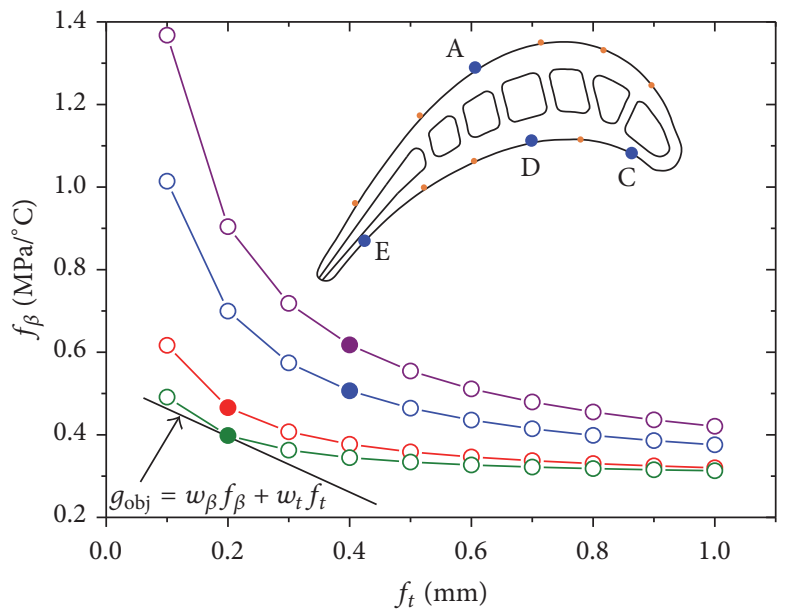

-O- Position A (pressure side) - - - Position D (suction side)

-O- Position C (leading edge) - - - Position E (trailing edge)

FIGURE 8: Pareto set for representative positions A, C, D, and E on the airfoil (the solid points denote the solutions of $g_{\mathrm{obj}}$ ).

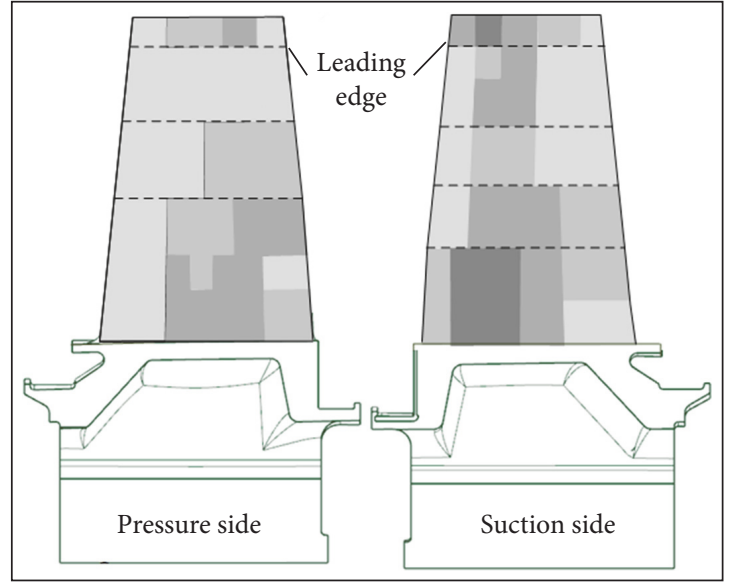

$0.5 \mathrm{~mm}$
$0.4 \mathrm{~mm}$

(a)

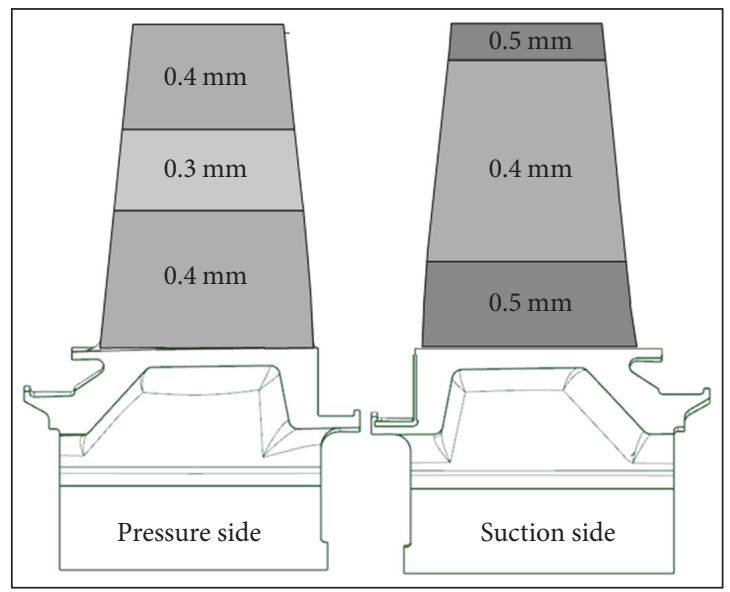

(c)

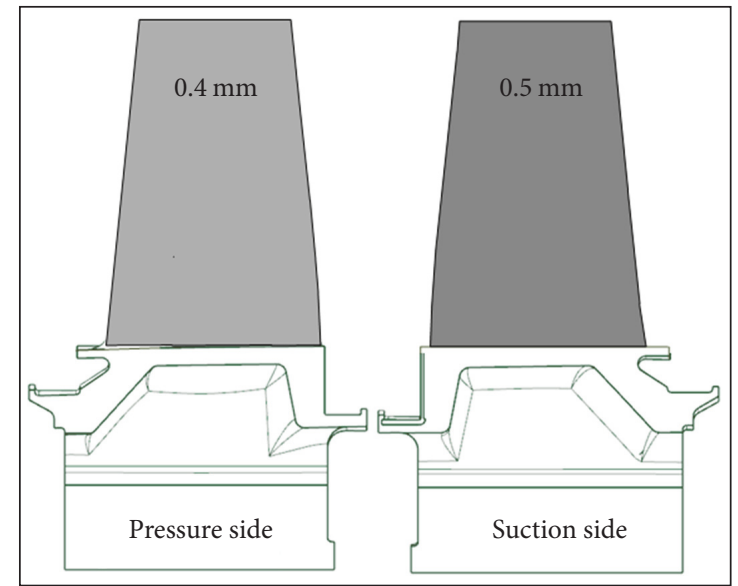

(b)

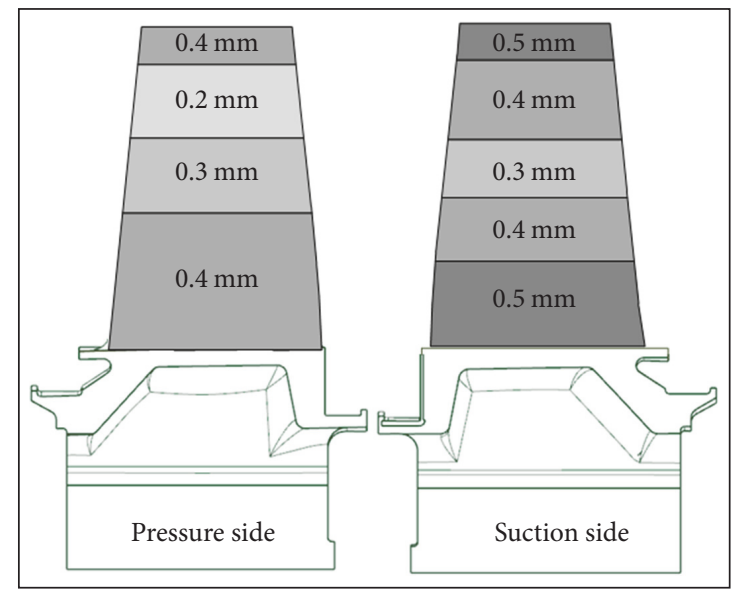

(d)

FIGURE 9: (a) Preliminary top-coat thickness distribution based on uniform-thickness analysis; (b) multiregion top-coat thickness distribution scheme 1; (c) scheme 2; and (d) scheme 3. 


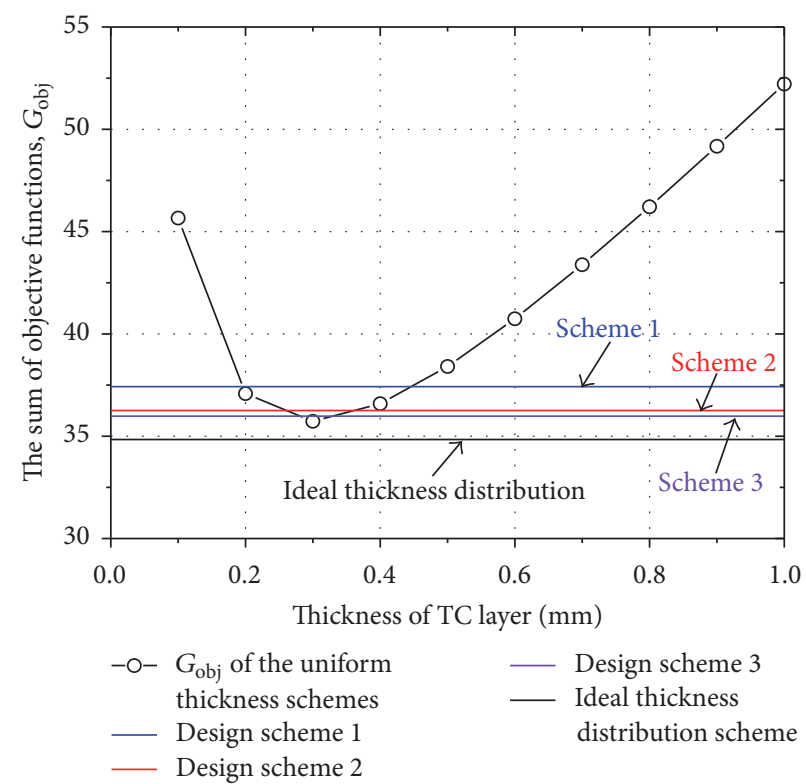

FIgURE 10: The sum of objective functions for various top-coat thickness distribution schemes.

distribution has the qualitatively similar appearance to the temperature field on substrate. The blade tip and bottom area need thicker TC than the middle region.

\subsection{Optimization Designed Multiregion Thickness Distribu-} tion. According to the preliminary results, we proposed three design schemes and then made comparison among them to find a suitable TC thickness distribution. In general, the design of coatings thickness distribution should take the practical spraying process into account. Due to the twisting feature of the airfoil, it is easier to spray the coatings by dividing the subregions along the vertical direction.

The proposed multiregion schemes are illustrated in Figures 9(b)-9(d), in which the pressure side and the suction side of the airfoil are dealt with separately. Both sides may be further divided into multiple subregions, where the TC thickness within a subregion is the same. Since a subregion contains several representative positions having different optimal TC thicknesses, we conservatively determine the thickness of a subregion equal to the highest value predicted within it. Generally, scheme 1 is designed having the fewest subregions and easiest fabrication process, but scheme 3 is reverse. The TC thickness of the platform in all schemes is assigned as $800 \mu \mathrm{m}$.

The FE model using the above three multiregion schemes was built and analyzed. And then $G_{\text {obj }}$ were calculated. For comparison, $G_{\text {obj }}$ of all the uniform-thickness schemes along with multiregion schemes are illustrated in Figure 10. It is seen that the values of $G_{\text {obj }}$ for uniform-thickness schemes rapidly increase for TC thickness above $500 \mu \mathrm{m}$, which indicates the low efficiency of TBCs with uniform TC thicker than it. Although the scheme of 300 um uniform thickness has low $G_{\text {obj, }}$, it fails to satisfy the thermal constraint condition, which is the temperature on the substrate of airfoil being no higher than $1000^{\circ} \mathrm{C}$.

In general, the difficulty in spraying the TBCs on the turbine blade is definitely enhanced when the thickness distributions scheme becomes complex. For multiregion schemes, $G_{\text {obj }}$ decreases with the increasing number of subregions, which means that more detailed dividing of subregions can help improve the comprehensive superiority of the scheme. However, the ideal thickness scheme contains so many subregions having different thicknesses that it is difficult to be implemented in the practical spraying process. Considering that $G_{\text {obj }}$ of scheme 2 are close to that of scheme 3 but the fabrication process is much easier, we suggest that scheme 2 is more suitable for engineering application.

Actually, $G_{\text {obj }}$ of these multiregion schemes have been initially estimated before above verification process. For a given multiregion scheme, $g_{\mathrm{obj}}^{i}$ of each position is directly calculated by using the results from uniform-thickness schemes. It is found that estimated $G_{\text {obj }}$ for schemes 1 to 3 are $37.5,36.4$, and 36.2, respectively. The corresponding values obtained in verification process are $37.4,36.3$, and 36.0, respectively. The differences are less than $6 \%$. Therefore, we conclude that estimating the superiority of a design scheme can be easily and quickly accomplished by using the results of uniformthickness schemes.

The temperature fields of the blade using design scheme 2 are illustrated in Figure 11. The temperature distribution on the airfoil of substrate is basically the superposition of the temperature fields of corresponding uniform-thickness schemes. The relative high temperature region is enlarged and temperature distributes more uniformly compared with that of uniform-thickness schemes.

The thermal stress distributions in TC and substrate are shown in Figure 12. The stresses within TC on the 


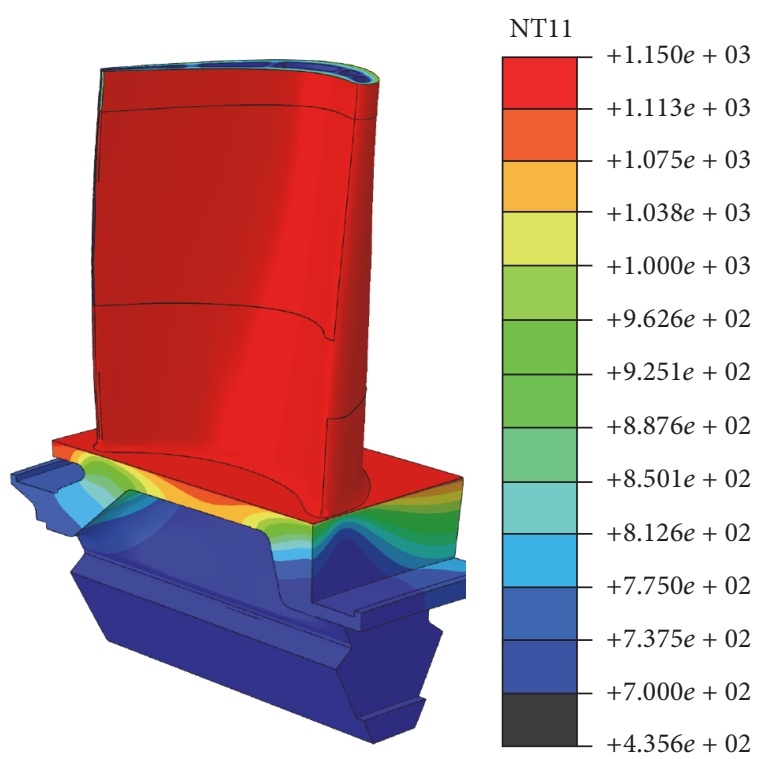

(a)

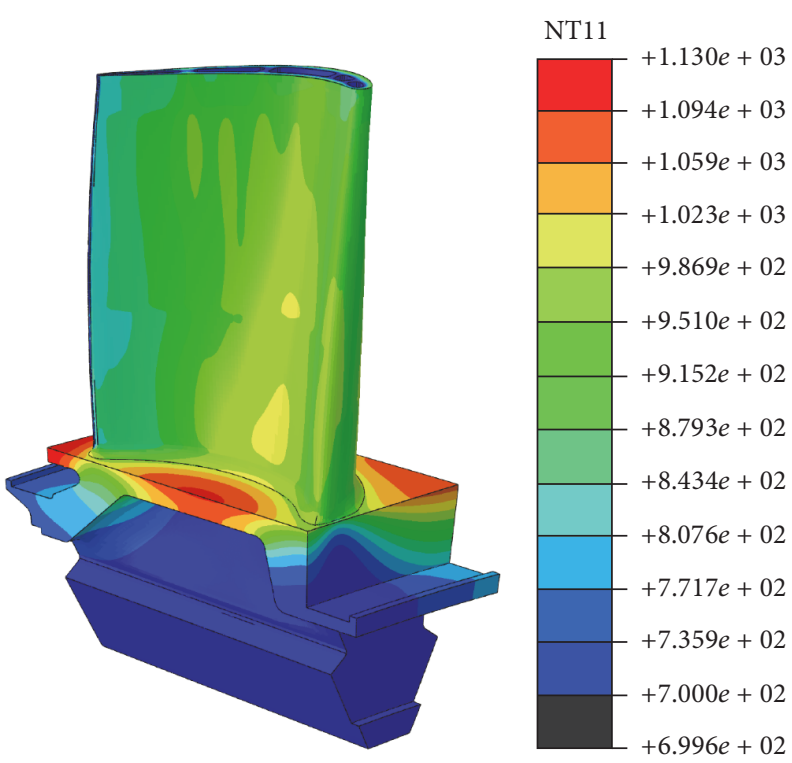

(b)

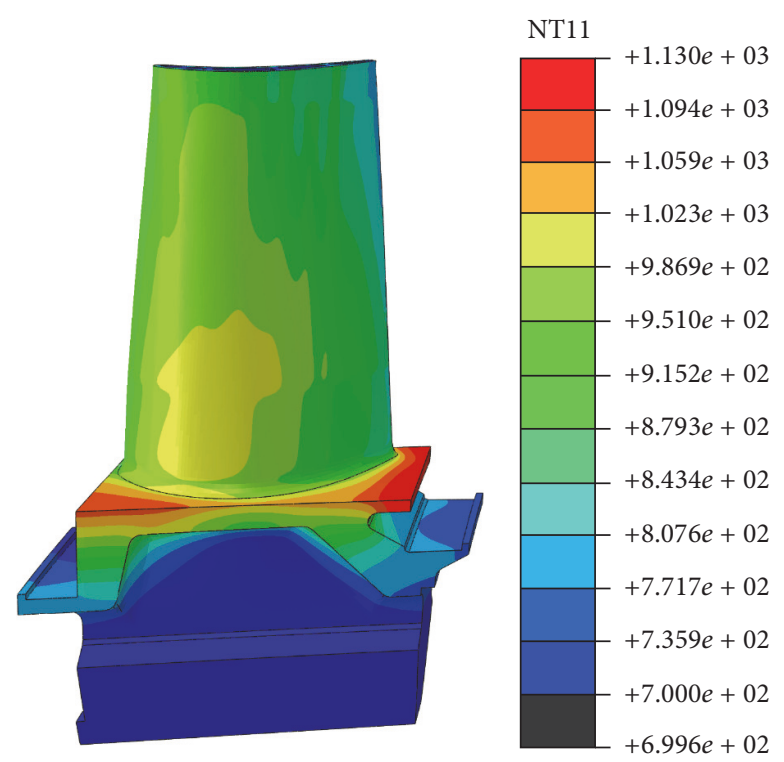

(c)

FIGURE 11: Temperature fields of the blade using design scheme 2: (a) overall model (with TBCs), (b) pressure side of the substrate (without TBCs), and (c) suction side of the substrate (without TBCs).

platform are higher than the ones of airfoil. Due to the imposed ENCASTRE boundary condition, the thermal stress at bottom part of the blade shank reaches a very high level, which is consistent with results from other studies [11].

\section{Conclusion}

This paper proposed a design method to obtain suitable thermal barrier coatings (TBCs) thickness distribution for a real gas turbine blade. Three-dimensional finite element model of the turbine blade with TBCs was built and analyzed, and the weighted-sum approach was used to solve the multiobjective optimization problem. The design method provides quantitative comparison for the selection of TBCs thickness so as to improve the efficiency of the coatings. It is found that the thermal insulation capability and stress level within the coatings on the blade airfoil are enhanced with the increase of top-coat thickness. Nevertheless, the thermal barrier effect of the coatings on the blade platform is not significant. For multiregion schemes, more detailed dividing of subregions can improve the comprehensive superiority of the scheme, but the fabrication difficulty should be considered accordingly. A three-subregion scheme is found to be suitable for engineering application. 


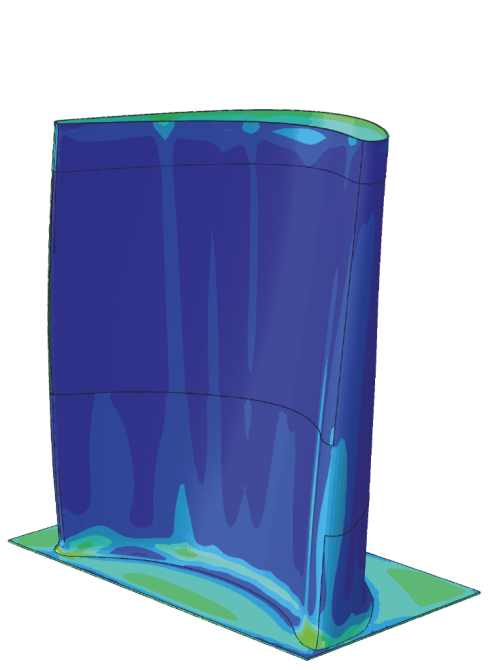

(a)

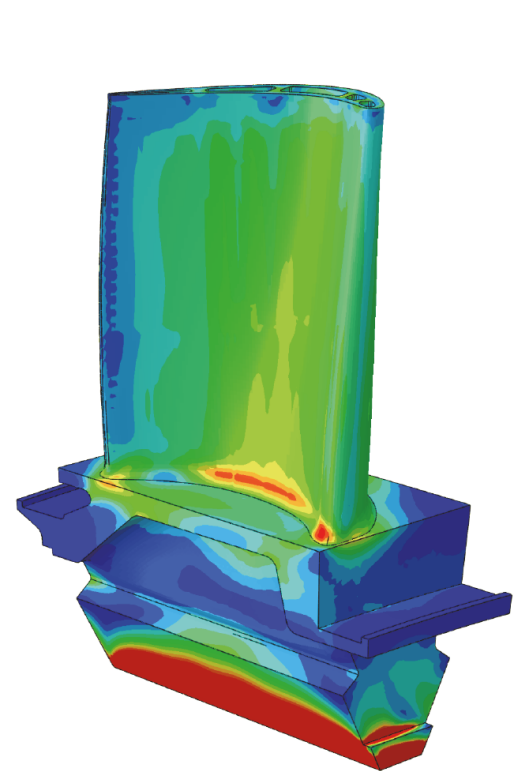

(c)
$S$, mises

(avg: 75\%)

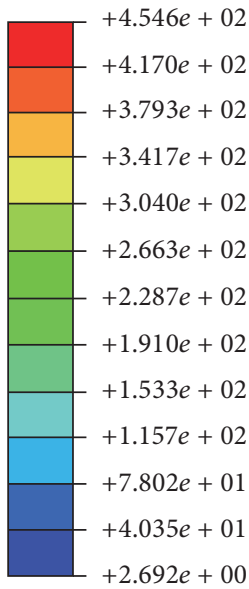

$+2.692 e+00$

S, mises
(avg: $75 \%)$

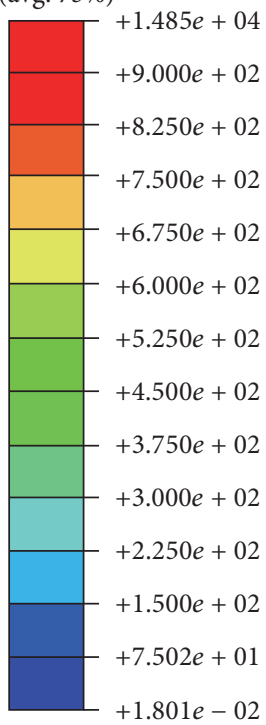

$+1.801 e-02$

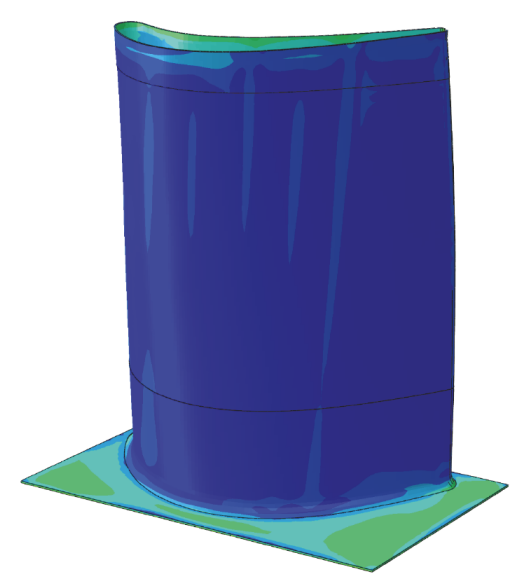

(b)

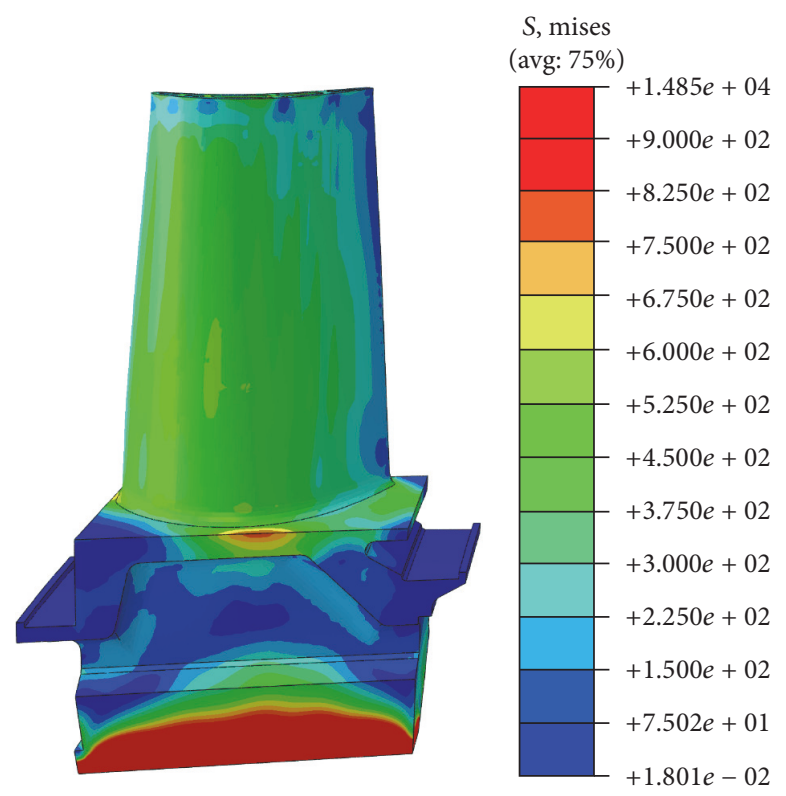

(d)

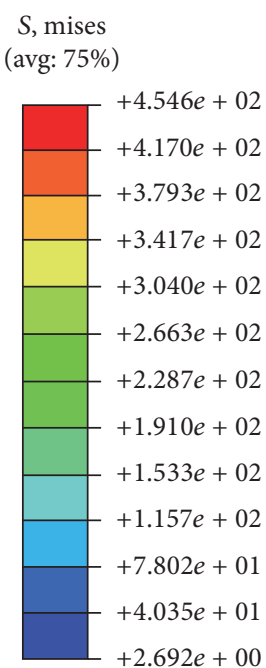

$+2.692 e+00$

$S$, mises (avg: $75 \%$ )

)

FIGURE 12: Thermal stress fields of the blade using design scheme 2: (a) pressure side of top-coat, (b) suction side of top-coat, (c) pressure side of the substrate, and (d) suction side of the substrate.

\section{Conflicts of Interest}

The authors declare that there are no conflicts of interest regarding the publication of this paper.

\section{Acknowledgments}

This work is supported by China 973 Program (2013CB035700) and National Natural Science Foundation of China (11472204 and 11602188).

\section{References}

[1] N. P. Padture, M. Gell, and E. H. Jordan, “Thermal barrier coatings for gas-turbine engine applications," Science, vol. 296, no. 5566, pp. $280-284,2002$.
[2] X. Fan, R. Xu, and T. J. Wang, "Interfacial delamination of double-ceramic-layer thermal barrier coating system," Ceramics International, vol. 40, no. 9, pp. 13793-13802, 2014.

[3] X. Q. Cao, R. Vassen, and D. Stoever, "Ceramic materials for thermal barrier coatings," Journal of the European Ceramic Society, vol. 24, no. 1, pp. 1-10, 2004.

[4] X. Fan, W. Jiang, J. Li, T. Suo, T. J. Wang, and R. Xu, "Numerical study on interfacial delamination of thermal barrier coatings with multiple separations," Surface and Coatings Technology, vol. 244, pp. 117-122, 2014.

[5] R. Ghasemi, R. Shoja-Razavi, R. Mozafarinia, and H. Jamali, "Comparison of microstructure and mechanical properties of plasma-sprayed nanostructured and conventional yttria stabilized zirconia thermal barrier coatings," Ceramics International, vol. 39, no. 8, pp. 8805-8813, 2013. 
[6] B. Li, Y. Li, and J. Su, "A combined interface element to simulate interfacial fracture of laminated shell structures," Composites Part B: Engineering, vol. 58, pp. 217-227, 2014.

[7] P. F. Zhao, C. A. Sun, X. Y. Zhu, F. L. Shang, and C. J. Li, "Fracture toughness measurements of plasma-sprayed thermal barrier coatings using a modified four-point bending method," Surface and Coatings Technology, vol. 204, no. 24, pp. 40664074, 2010.

[8] Y. Sun, W. Zhang, J. Li, and T. J. Wang, "Local stress around caplike portions of anisotropically and nonuniformly grown oxide layer in thermal barrier coating system," Journal of Materials Science, vol. 48, no. 17, pp. 5962-5982, 2013.

[9] S. Kim, J. Go, Y.-G. Jung, and J.-H. Lee, "Thermoelastic characteristics in thermal barrier coatings with a graded layer between the top and bond coats," Mathematical Problems in Engineering, vol. 2013, Article ID 515792, 8 pages, 2013.

[10] Y.-S. Choi and K.-H. Lee, "Investigation of blade failure in a gas turbine," Journal of Mechanical Science and Technology, vol. 24, no. 10, pp. 1969-1974, 2010.

[11] J. Hou, B. J. Wicks, and R. A. Antoniou, "An investigation of fatigue failures of turbine blades in a gas turbine engine by mechanical analysis," Engineering Failure Analysis, vol. 9, no. 2, pp. 201-211, 2002.

[12] V. N. Rao, I. N. N. Kumar, N. Madhulata, and A. Abhijeet, "Mechanical analysis of 1st stage marine gas turbine blade," International Journal of Advanced Science and Technology, vol. 68, pp. 57-64, 2014.

[13] M. Alizadeh, A. Izadi, and A. Fathi, "Sensitivity analysis on turbine blade temperature distribution using conjugate heat transfer simulation," Journal of Turbomachinery, vol. 136, no. 1, Article ID 011001, 2013.

[14] K. M. Kim, J. S. Park, D. H. Lee, T. W. Lee, and H. H. Cho, "Analysis of conjugated heat transfer, stress and failure in a gas turbine blade with circular cooling passages," Engineering Failure Analysis, vol. 18, no. 4, pp. 1212-1222, 2011.

[15] T. Sadowski and P. Golewski, "The influence of quantity and distribution of cooling channels of turbine elements on level of stresses in the protective layer TBC and the efficiency of cooling," Computational Materials Science, vol. 52, no. 1, pp. 293-297, 2012.

[16] Y. H. Sohn, E. Y. Lee, B. A. Nagaraj, R. R. Biederman, and R. D. Sisson Jr., "Microstructural characterization of thermal barrier coatings on high pressure turbine blades," Surface and Coatings Technology, vol. 146-147, pp. 132-139, 2001.

[17] I. Gurrappa and A. S. Rao, "Thermal barrier coatings for enhanced efficiency of gas turbine engines," Surface and Coatings Technology, vol. 201, no. 6, pp. 3016-3029, 2006.

[18] L. Yang, Q. X. Liu, Y. C. Zhou, W. G. Mao, and C. Lu, "Finite element simulation on thermal fatigue of a turbine blade with thermal barrier coatings," Journal of Materials Science \& Technology, vol. 30, pp. 371-380, 2014.

[19] W. Zhu, M. Cai, L. Yang, J. W. Guo, Y. C. Zhou, and C. Lu, “The effect of morphology of thermally grown oxide on the stress field in a turbine blade with thermal barrier coatings," Surface and Coatings Technology, vol. 276, pp. 160-167, 2015.

[20] M. Bäker, "Influence of material models on the stress state in thermal barrier coating simulations," Surface and Coatings Technology, vol. 240, pp. 301-310, 2014.

[21] M. Y. He, J. W. Hutchinson, and A. G. Evans, "Simulation of stresses and delamination in a plasma-sprayed thermal barrier system upon thermal cycling," Materials Science and Engineering A, vol. 345, no. 1-2, pp. 172-178, 2003.
[22] N. Asok Kumar and S. R. Kale, "Numerical simulation of steady state heat transfer in a ceramic-coated gas turbine blade," International Journal of Heat and Mass Transfer, vol. 45, no. 24, pp. 4831-4845, 2002.

[23] Y. C. Zhou and T. Hashida, "Coupled effects of temperature gradient and oxidation on thermal stress in thermal barrier coating system," International Journal of Solids and Structures, vol. 38, no. 24-25, pp. 4235-4264, 2001.

[24] M. Ranjbar-Far, J. Absi, G. Mariaux, and F. Dubois, "Simulation of the effect of material properties and interface roughness on the stress distribution in thermal barrier coatings using finite element method," Materials and Design, vol. 31, no. 2, pp. 772781, 2010.

[25] L. Su, W. Zhang, X. Chen, and T. J. Wang, "Experimental investigation of the biaxial strength of thermal barrier coating system," Ceramics International, vol. 41, no. 7, pp. 8945-8955, 2015.

[26] I. Y. Kim and O. L. De Weck, "Adaptive weighted-sum method for bi-objective optimization: pareto front generation," Structural and Multidisciplinary Optimization, vol. 29, no. 2, pp. 149158, 2005.

[27] R. T. Marler and J. S. Arora, "The weighted sum method for multi-objective optimization: new insights," Structural and Multidisciplinary Optimization, vol. 41, no. 6, pp. 853-862, 2010.

[28] K. Deb, "Multi-objective optimization," in Search Methodologies, pp. 403-449, Springer, 2014.

[29] E. Zitzler and L. Thiele, "Multiobjective evolutionary algorithms: a comparative case study and the strength Pareto approach," IEEE Transactions on Evolutionary Computation, vol. 3, no. 4, pp. 257-271, 1999.

[30] S. Y. Wang, K. Tai, and M. Y. Wang, "An enhanced genetic algorithm for structural topology optimization," International Journal for Numerical Methods in Engineering, vol. 65, no. 1, pp. 18-44, 2006.

[31] R. C. Eberhart and Y. Shi, "Particle swarm optimization: developments, applications and resources," in Proceedings of the Congress on Evolutionary Computation, vol. 1, pp. 81-86, IEEE, Seoul, Republic of Korea, May 2001.

[32] P. J. van Laarhoven and E. H. Aarts, Simulated Annealing: Theory and Applications, Kluwer Academic Publishers, 1987. 


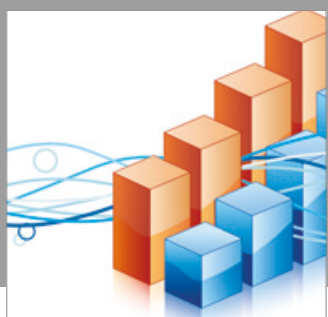

Advances in

Operations Research

vatersals

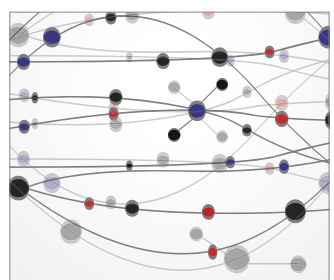

\section{The Scientific} World Journal
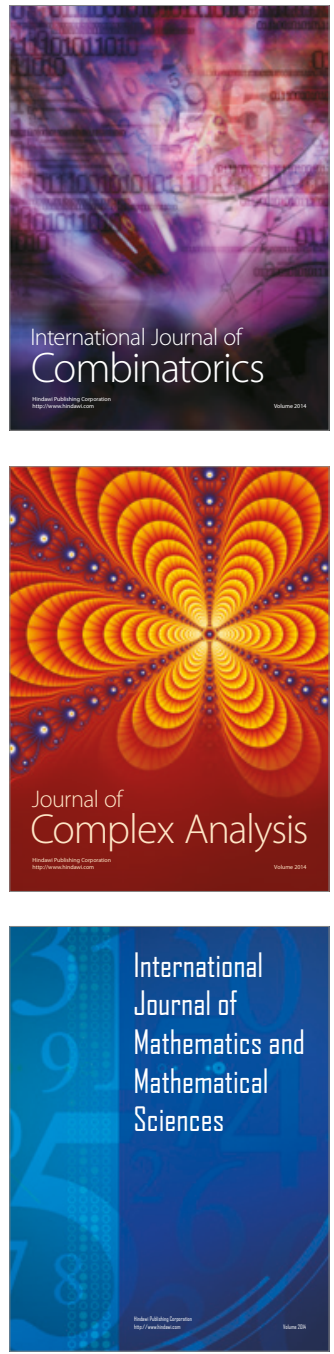
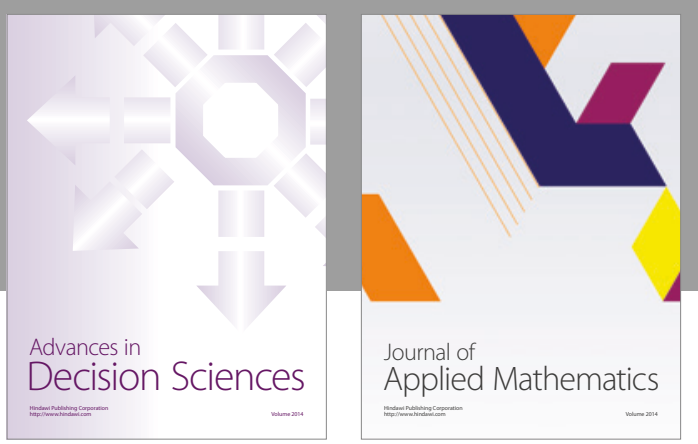

Algebra

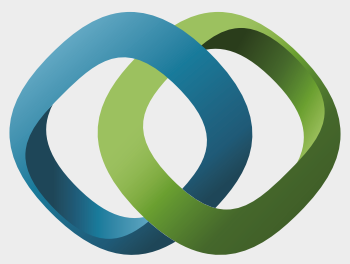

\section{Hindawi}

Submit your manuscripts at

https://www.hindawi.com
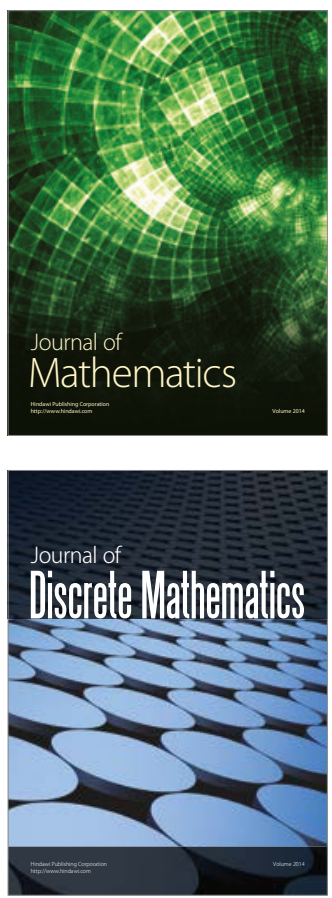

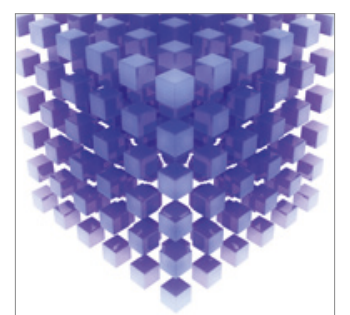

Mathematical Problems in Engineering
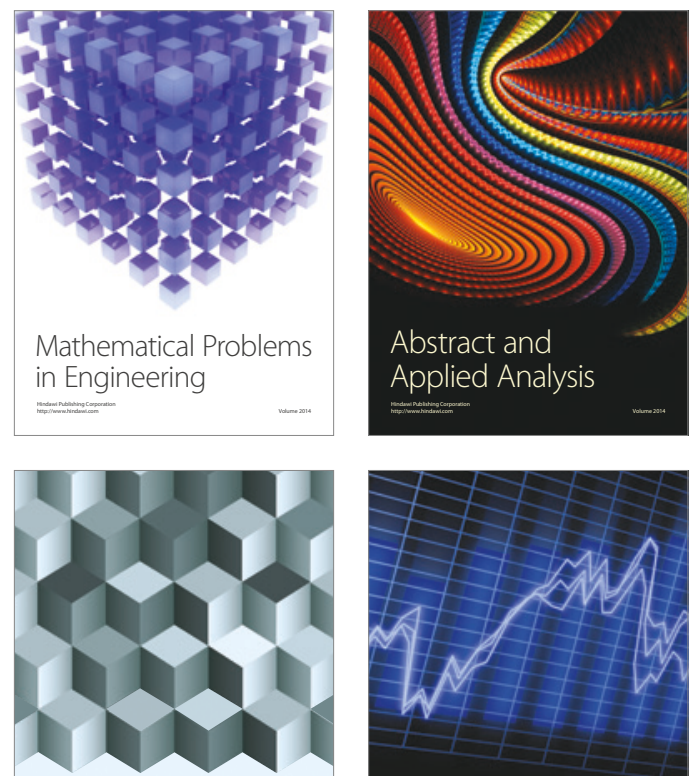

Journal of

Function Spaces

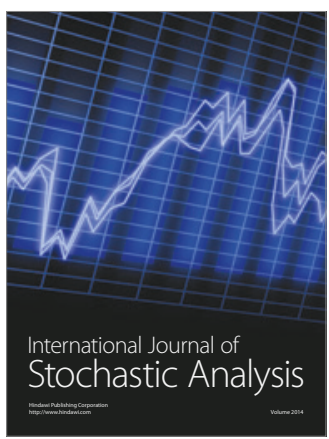

Probability and Statistics
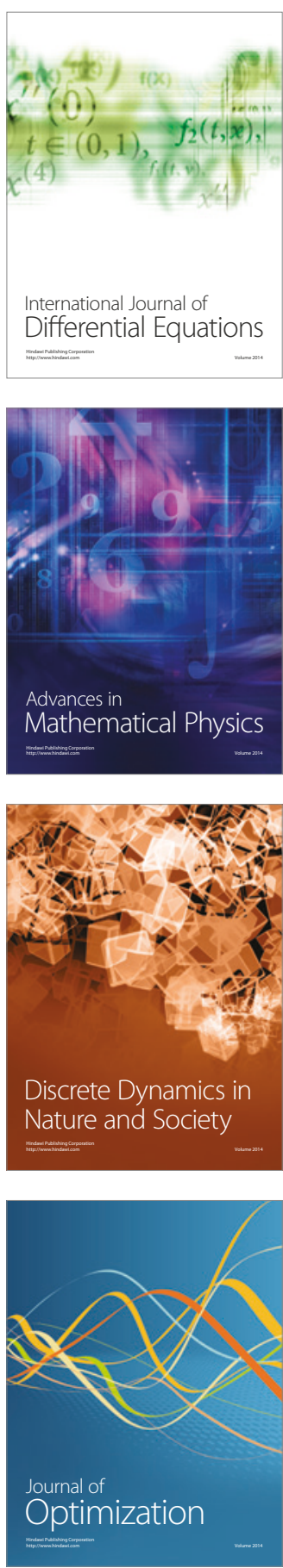